\title{
Finite size scaling in the local abundances of geographic populations
}

\author{
Sebastián R Abades ${ }^{1,2,3}$ and Pablo A Marquet ${ }^{1,2,3,4}$ \\ ${ }^{1}$ Center for Advanced Studies in Ecology and Biodiversity (CASEB), Departamento de Ecología, Pontificia Universidad Católica de Chile, Santiago, Chile. \\ 2 Institute of Ecology and Biodiversity, Universidad de Chile, Santiago, Chile. \\ ${ }^{3}$ Laboratorio Internacional en Cambio Global (CSIC-PUC), Esporles 07190, Spain \\ ${ }^{4}$ The Santa Fe Institute, 1399 Hyde Park Road, Santa Fe, New Mexico 87501 USA.
}

\begin{abstract}
We analyzed the statistical distribution of intra-specific local abundances for a set North American breeding bird species. We constructed frequency plots for every species and found that they showed long-tail power-law behavior, truncated at an upper abundance cut-off value. Based on finite size scaling arguments, we investigated whether frequency curves may be considered scaled copies of each other. Data collapse was possible after taking powers of the total abundance of each species, in order to correct deviations from the underlying universal finite size scaling function (UFSS). The UFSS power law exponent oscillated in time within the regime of unbounded variance, which is consistent with the wild fluctuations that characterize ecological phenomena. We speculate that our results may eventually be linked to other law-like macroecological phenomena, such as energetic constraints reported in allometric scaling.
\end{abstract}

Keywords: finite size scaling, geographic population, data collapse, truncated power-law, Bose-Einstein distribution, scaling.

\section{INTRODUCTION}

Animal density rarely occupies space uniformly. Rather, individuals are found forming groups, the size of which depends on many factors (Bonabeau et al., 1999). For instance, environmental gradients in habitat quality can generate variations in density due to differences in carrying capacity (Doebeli and Dieckmann, 2003; Kirkpatrick and Barton 1997). The benefits of aggregation include reduction of predation rates (Morgan, 1988), increased foraging efficiency (Mogilner et al., 2003), and reproduction success (Warburton and Lazarus 1991), to mention just a few. In any case, the tendency to crowd is a widespread pattern of nature, and has interested ecologists for a long time (e.g., Bonabeau et al., 1999; Flierl et al., 1999; Gueron and Levin, 1995; Higashi and Yamamura, 1993; Niwa, 1994, 1996; Okubo, 1986; Okubo and Levins, 2001).

Any given species has an associated probability distribution that summarizes the spectrum of abundances attained at different locations (e.g. Bonabeau et al., 1999, McGill et al. 2007). A comprehensive description of the statistical pattern of local abundances is key for understanding the evolution of species crowdedness (Niwa, 1994; Okubo, 1986). For instance, the existence of a typical density may suggest that such a density yields an optimal balance between the cost of living closer to conspecifics, and the benefit of assuring reproductive success (Bonabeau et al., 1999; Higashi and Yamamura, 1993). This optimality notion, however, becomes useless when we attempt to describe the large array of populations that comprise the full geographic extent of a species (Niwa, 1996, 1998, 2004, Pascual et al., 2002; Roy et al., 2003). This occurs because local densities may vary so widely from place to place that the very notion of a typical density becomes problematic. Furthermore, when the maximum density at a few locations is large, as compared to the background abundance, the resulting probability distribution may exhibit a long tail, a possibility that has been overlooked in most population studies (Bonabeau et al., 1999).
In fact, it has been recently argued that several quantities of ecological interest may present a power-law form in frequency or probability distributions (e.g., Marquet et al., 2005; Niwa, 2003).

In this report we are concerned with the patterns of variation in the local abundance observed across the geographical range of species. Questions about the distribution of ecological attributes across geographic space have usually been addressed in the context of macroecological theory (e.g.,Brown, 1995; Gaston and Blackburn, 2000; Marquet 2002; Maurer, 1999) by using average density, and thus implicitly assuming that the probability distributions describing them possess a characteristic scale (i.e., a typical density) and shorttails. Nevertheless, a growing amount of evidence suggests that this may not always be the case, and that long-tailed abundance distributions could be more the rule than the exception in nature (Bonabeau et al., 1999; Gueron and Levin 1995; Higashi and Yamamura 1993; Marquet 2000; Marquet et al., 2005; Sornette, 2000; Stauffer 2000). This postulate is far from trivial, because some long-tailed distributions may show divergence in one or more of its statistical moments. In particular, for the case of power-law distributions, unbounded variance can take place when the second and upper moments diverge. Sometimes even the first moment diverges, and a typical size value and characteristic scale is absent (Sornette, 2000; Stanley, 1987).

From a methodological point of view, it is always convenient to explore the statistical distribution of abundances and check whether or not they present signatures of power-law. Besides pure methodological interest, power-law distributions are also important from a more theoretical perspective. There is growing evidence that some ecological scaling may be the outcome of an underlying critical organization, either in the form of self-organized criticality or as found in second order phase transitions (Bonabeau at al., 1999; Keitt and Marquet, 1996; Keitt and Stanley, 1998; Milne et al., 1996; Niwa, 2003; Pascual et al., 2002; Rhodes et al., 1997; Roy et al., 2003). This is an interesting 
conjecture, because critical scaling behavior is connected to the notion of universality classes, a powerful concept used in statistical physics to systematically compare and recognize as similar (based on the value of their critical exponents), systems that would otherwise be considered as different, if the attention were put in the nature of their components or microscopic details (Bonabeau and Dagorn 1995; Mantegna \& Stanley, 2000; Stanley, 1995; Stanley et al., 2000; Vicsek, 2001; Yeomans 1992). More specifically, the term universality is used by physicists to highlight the idea that near a critical point of organization (i.e., a continuous phase transition), systems composed of multiple elements show spontaneous order that is not attributable to the details of the individual particles that constitute the system, or the specific details of the rules that govern the relationships among them. Rather, other macroscopic features of the system become relevant, such as its dimensionality (Gisiger, 2001). Thus, universality complies with the very definition of a complex systems.

Our study system will be a set of species taken from the North American breeding bird survey. This system is ideally suited for this type of analyses as it represents one of the few continental-scale censuses available for a large ensemble of species. We hypothesize that conspecific breeding bird individuals self-organize in space by forming aggregates in demand of suitable habitats for reproduction (Gueron and Levin, 1995; Higashi and Yamamura, 1993; Maurer, 2005; Niwa, 1994, 1996). In addition, we propose testing for the existence of a specific type of statistical distribution, the Bose-Einstein distribution. This is a suitable null statistical distribution as it assumes that the elements that are being arranged into distinctive classes are identical. Thus, Bose-Einstein statistics (hereafter B-E) postulate that each distinguishable combination of $r$ elements (e.g., individuals) in $n$ groups (e.g., abundance classes) has equal probability of occurrence. The resulting probability distribution shows a truncated power-law behavior, which is in contrast to the expected exponential distribution (i.e. Gibbs-Boltzmann) that arises under the distinguishable assumption of microstates (Ijiri \& Simon, 1975). It turns out to be an appropriate null model under a neutral scenario as has been postulated by Hubbell (2001), where individuals of different species are assumed to be equivalent on a per capita basis. Accordingly, if breeding places across the geographical range are considered a limited resource for individuals seeking to breed, an intraspecific B-E distribution should be verified. Interestingly, and in analogy with animal behavior, particles obeying B-E distribution are believed to exert attraction on other particles, by exciting a particular energy state, producing a quantum effect named Bose-Einstein condensation (hereafter, $\mathrm{BEC})$. In an ecological context, this biosocial contagion mechanism is ethologically justified, and, in analogy to BEC phenomena, is expected to be responsible for producing an exponentially truncated power-law frequency distribution of local abundances, similar to those observed in other ecological aggregates (Majumdar and Sire, 1993; Mogilner et al., 2003; Rajesh and Majumdar, 2001; Takayasu et al., 1988, 1989; Takayasu, 1989, Taylor and Taylor, 1977; Vicsek et al., 1985). Borrowing some thermal physics jargon (Gould et al., 2006; Stanley, 1987; Yeomans, 1992), we may say that abundance undergoes a type of phase transition from a high temperature regime (where abundance classes are occupied according to the Gibbs law, see Okubo, 1986), to a more cooled phase (where spatial coalescence tends to favor a scale invariant occupation of abundance classes). We leave the problem of characterizing ecological phase transitions to a forthcoming report and point the interested reader to Pascual et al. (2002), Pascual and Guichard (2005)and Roy et al. (2003). Instead, in this report we will address the question of characterizing the frequency distribution of local abundances within the geographic range of species, and test whether universality underlies abundance scaling.

\section{METHODS}

Database

We analyzed the statistical distribution of local abundance across the geographical range of bird species using the North American Breeding Bird Survey database. This survey has been conducted by the United States Geological Survey since 1966 to the present, and consists of the permanent census of about 2,500 routes visited yearly by volunteer ornithologists during the breeding season (Peterjohn and Sauer, 1999). The sampling grid has a spatial coverage extending over all the continental territory of the United States and southern Canada. In every route, ornithologists have identified resident species and obtained an estimate of their local abundance, based on visual or sound recordings. From this database, we selected a random set of 67 species whose geographical ranges were totally or mostly contained inside the boundaries of the sampling region. We used data from years 1980 to 2002, and performed our analysis on a yearly basis. Except for size effects (see below), we treated these selected species as being fundamentally equivalent, hence, we did not keep track of their specific taxonomic identity in the remainder of this report. However, chosen species differ in many respects, encompassing at least three orders of magnitude in body mass, overlapping in geographic extent in various degrees, differing in habitat use and diet, not to mention the many differences in abundance levels and degrees of spatial occurrence. The only similitude criteria used to select the current set of species from the whole BBS database was that they were permanent resident species, so as to avoid effects of inter-year long-distance migration on the patterns of abundance observed across space.

\section{Power law distributions and data collapse}

Power-law distributions take the form $N(s) \sim s^{-\beta}$, where $N(s)$ is the frequency of sites having $S$ individuals, and $\beta$ is the power-law exponent that governs slow frequency decay (Marquet et al., 2005, Niwa, 2003, 2005; Stanley, 1995). For $|\beta|>2$ the distribution has infinite variance (Sornette, 2000). In practical terms, infinite variance refers to the idea that, no matter how much we increase the sampling effort, variance will always increase. For $|\beta|>1$ the mean diverges to infinity (Sornette, 2000). However, empirical power-laws are necessarily truncated at a maximum cut-off value (Bonabeau et al., 1999; Chave and Levin, 2003; Niwa, 2005), because the total number of individuals of one species is finite. We incorporated finite size effects into our analysis by assuming the ansatz

$$
N(s)=L^{\alpha} f\left(s \times L^{-\gamma}\right)
$$

where $L$ is a term representing the size of the system under study, considered here as the total abundance of each species, 
while $\alpha$ and $\gamma$ are suitable powers used to correct system size effects. According to eq. 1, size effects are introduced by a truncation point modulated by $L^{-\gamma}$, and a normalizing effect through $L^{\alpha}$ (Sornette, 2000; Stauffer and Aharony, 1992). A strong finite size effect can create bending in the probability curve, reinforcing the B-E exponential truncation. Thus the powers coefficients $\alpha$ and $\gamma$ contain information about the intrinsic truncation present in B-E distributions and deviations generated by finite size effects. The latter bending effect also interferes with the expression of the power-law behavior present in B-E below the exponential cut-off. In order to remove these effects, and recover the asymptotic distributional form, we performed a finite size scaling (FSS) analysis (Fisher and Barber, 1972; Niwa, 2005). First, we defined the scaled variables

$$
\begin{aligned}
& y=N(s) \times L^{-\alpha} \\
& x=\frac{s}{L^{\gamma}}
\end{aligned}
$$

Then, estimates of $\alpha$ and $\gamma$ were obtained by data collapse (Niwa, 2003, 2004, 2005). We iteratively searched the values for both parameters that placed all species frequency plots on a single curve (if it existed). Our best collapse was achieved by minimizing the mean of the two-dimensional variance (Cont and Bouchard, 2000). To do this, we defined the twodimensional variance as

$$
\varepsilon_{i}=\left(\frac{\sigma_{X}}{\bar{x}}\right)^{2}+\left(\frac{\sigma_{y}}{\bar{y}}\right)^{2}
$$

where $\bar{x}$ and $\bar{y}$ are the mean of eq. (2) and eq. (3) respectively, while $\sigma$ is their standard deviation. These values were calculated on every $\varepsilon_{i}$ block defined after suitably binning the $x$-axis with boxes of regular size (Niwa, 2004). The mean value of $\varepsilon_{i}$ was used as the quantity to be minimized, and as a measure for the goodness of fit for data collapse (Cont and Bouchard, 2000).

The analysis outlined above was done on every species, using bird counts at the level of routes to describe the statistical behavior local abundances. We constructed histograms of abundance by the method of exponential binning, as suggested in Marquet et al. (2005) and Pueyo (2006). Afterwards, we made the FSS analysis on a yearly basis, and acquired estimates of $\beta$ for the power-law range of the collapsed curves. The resulting time series of $\beta$ was used to investigate whether FSS was consistent over time.

\section{RESULTS AND DISCUSSION}

Figure 1 shows the local abundance frequency plots for all the species under analysis. We only plotted data for 2002 in order to illustrate differences among curves. It is clear that species differ in the relative frequency of different abundant classes, and degree of curvature. Besides those apparent discrepancies, it is possible to discern a power-law regime in the middle range of the plot (note the double logarithmic scale).

For FSS we found that minimization of the two-dimensional variance was attained at $\alpha=0.28$ and $\gamma=0.46$. Figure 2 shows the plane of numerical solutions for different combinations of both parameters. The cross mark indicates the global minimum for which data collapse was attained. Note that there are two other local minima, corresponding to values that result in a good collapse either around the cut-off region or around $\mathrm{N}(1)$. Using eqns. 3 and 4, we calculated the scaled variables $x$ and $y$, resulting in the data collapse shown in Figure 3.

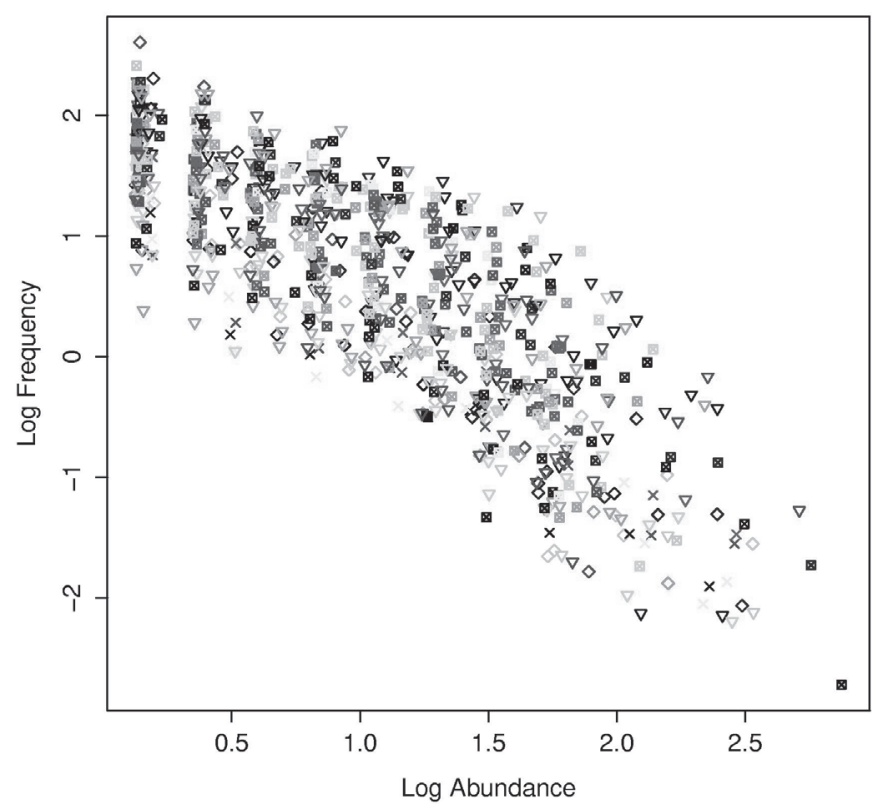

Figure 1: Frequency distribution for local abundance across the geographic range of breeding birds. Each combination of intensity and symbol represents one species. Data correspond to 2002 only.

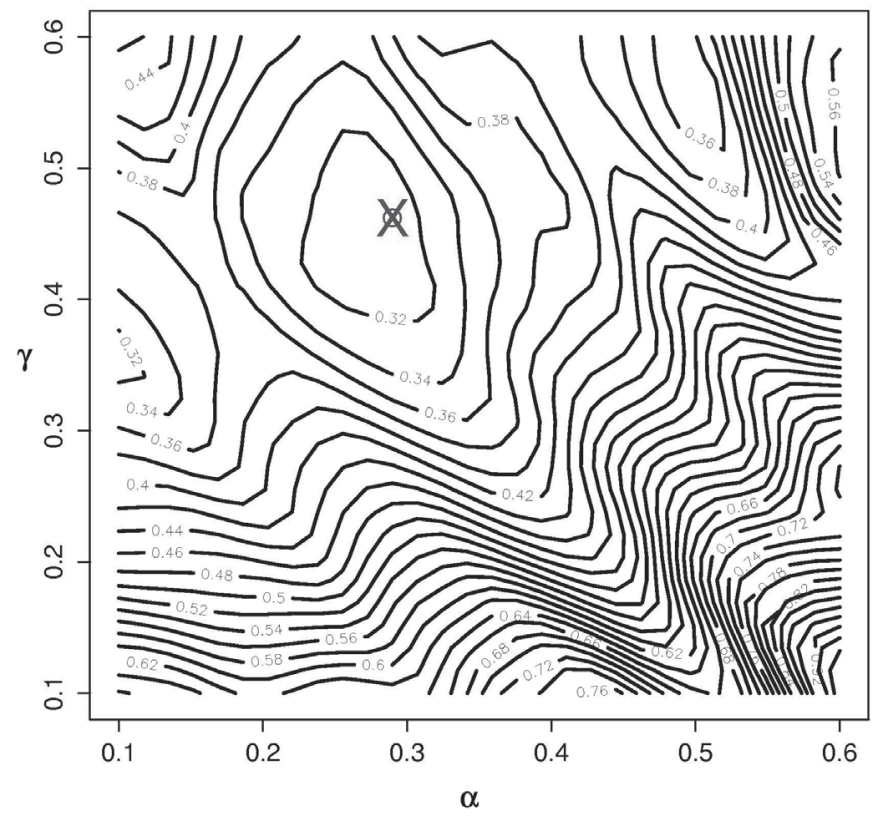

Figure 2: Solution space for the mean two-dimensional variance as a function of system size power exponents. Isoclines represent values of $\varepsilon$ across different trials of $\alpha$ and $\gamma$. The cross shows the position for the global minimum. 


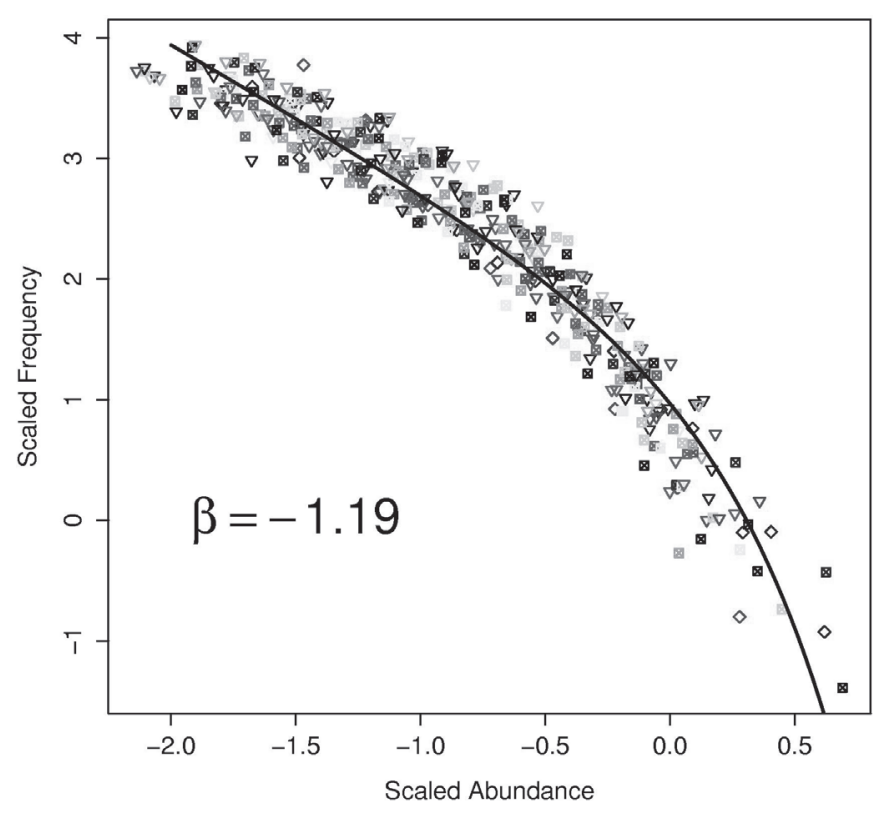

Figure 3: Data collapse for the abundance distribution curves shown in Figure 1. The line indicates the predicted curve using the FSS estimate of $\beta$.

All curves collapsed well into a unique universal finite-size scaling curve (UFSS). These results are in qualitative agreement with similar analysis conducted on fish school sizes (Bonabeau and Dagorn, 1995; Bonabeau et al., 1999; Niwa 1998, 2004; Rinaldo et al., 2002), although exponent values were different in all cases. This similarity is worth noting, because our data resulted from processes occurring at much larger spatial and temporal scales than in those studies, and yet, results qualitatively agreed.

Figure 4 shows the temporal evolution of $\beta$ values for the period 1980-2002. This sequence did not show any temporal trends, but does present oscillations with a 5-6 year periodicity, suggesting that UFSS is robust over time, and that robustness may be achieved by compensating deviations around a long-term asymptotic value. Note that despite the observed fluctuations, $\beta$ never reached values outside the region where the first statistical moment is well-defined, suggesting that the UFSS curve has a well located theoretical mean, but its estimation will always be obscured by fluctuations associated with the divergence of the variance.

So far we have provided a pure phenomenological approach that accounted for the existence of universal behavior in the system under study. It has been shown that there is an underlying truncated power-law with exponent $|\beta|=1.19$, which is in agreement with exponents reported for avalanche-like statistics (Turcotte, 1999). This UFSS curve can be regarded as the master curve from which every species is a particular realization that has been distorted by finite size effects. Thus, it is natural to ask: What are the factors responsible for such deviations? We cannot provide a comprehensive response to this question at this point. However, we can sketch out an explanation resorting to the implications of being governed by a B-E distribution, briefly reviewed in the following paragraph.
In B-E formalism, the leading process is competition for empty energy states. Imagine an energy state as the amount of energy required to sustain a given number of individuals (note that in this transformation we are changing from a continuous version of energy to a discrete version, where energy is shaped into the boundaries of a single individual, therefore the analogy with quantum mechanics becomes useful). This notion assumes two things: i) an energy state is proportional to the number of organisms it can sustain and, ii) competition for energy takes place before competition among individuals. In addition, assume competition is taking place over a finite energy landscape, so resources are limited. Given that energy is limited, its depletion by one species not only reduces the number of new individuals that can be allowed in a given energy state, but most importantly, the number of possible energy states is also reduced. This occurs because a lesser amount of energy can be partitioned in fewer ways than a larger amount. Thus, whereas energy is exhausted, larger energy states progressively disappear, and the potential remaining energy states will only allow for a lesser number, and size, of incoming individuals. This scenario resembles the macroecological stage, where resources are known to be finite and species, although different in size, tend to be equivalent in the amount of energy they use within ecosystems (Brown et al., 1993; Brown, 1995), at the cost of achieving different densities. Accordingly, it is likely that species will interfere among them by affecting the size of energy states related to the universal B-E abundance distribution, and, as a consequence, distortions are accrued on it. Figure 5 graphically explains our argument. Whether this phenomenology holds true, and concurs with observed macroecological size scaling patterns, remains to be tested.

The relationship between FSS and allometric scaling remains to be explored. If FSS in abundance could be linked to energetic constraints through body mass, it would pose an interesting scenario, in which one set of scaling rules may deviate or even suppress the validity of another.

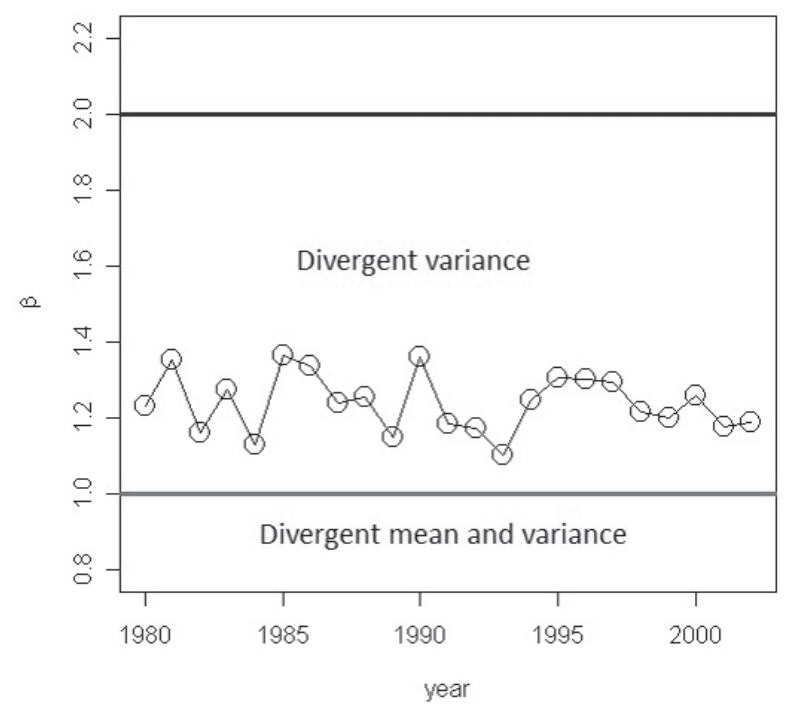

Figure 4: Temporal fluctuations of the absolute value of scaling exponent $\beta$. The blue line shows the limit below which variances diverge. Green line shows the limit of mean and variance divergence. 
(a)

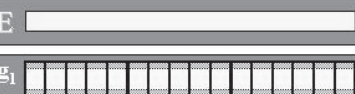

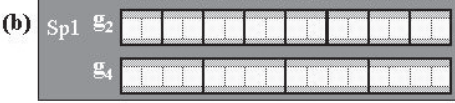

(c)
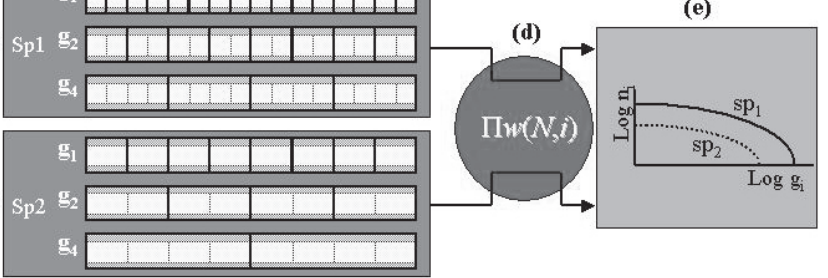

(f)

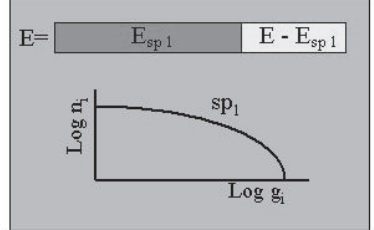

(g)

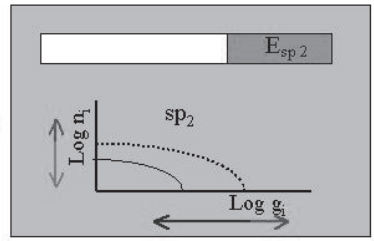

Figure 5: Diagrammatic representation of the origin of finite size effects in intra-specific patterns of abundance. We start considering a finite amount of energy $E$, represented by the solid bar in (a). We considered only two species, $S p_{1}$ and $S p_{2}$ with different body sizes, such that $m_{1}<m_{2}$. These species attempt to use energy by partitioning $E$ into $i-1$ energy states $e_{\mathrm{i}}$ within which individuals will reside forming groups of size $g_{\mathrm{i}}=e_{\mathrm{i}} / m_{\mathrm{i}}$. Species $S p_{1}$ has $w(N, i)$ forms to combine $N$ individuals into $i$ - $t$ equally sized partitions. This is represented in (b) by groups of size $g_{1}, g_{2}$ and $g_{4}$, indicated by big white squares. Small squares represent individuals whose size $m_{\mathrm{i}}$ allows them to fit into $g_{\mathrm{i}}$. In (c) we repeat the process of partitioning for species $S p_{2}$, twice as large as $S p_{1}$. For any one species, all possible combinations between $N$ and $i$, are represented in (d) as the product between all possible $g_{i}$ states. The solution for this generating process has been shown to have the form of a truncated power-law probability distribution (e). For an infinite value of $E_{1}$ curves for $S p_{1}$ and $S p_{2}$ should converge. For finite but very large values of $E$, probability functions would be identical in shape, but displaced in some amount related to body size (solid versus dotted lines in (e)). In (f) we show the imaginary situation in which one species (e.g. $S p_{1}$ ) took over a fraction of energy $E_{S p 1}$ from a limited energy stick $E$. This leaves a reduced portion $E_{S p 2}=E-E_{S P 1}$ of energy available to species $E_{S p 2}$ for converting it into individuals. We sketch this situation in (f), by showing the displacement induced by this finite size constraint upon the asymptotic abundance frequency distribution of $S p_{2}$ (i.e., change from dotted to thin solid line). The displacement may occur in any direction, depending on the size of $S p_{2}$. In this case we have assumed $m_{1}<m_{2}$, making a shift along the direction of arrows more likely.

\section{ACKNOWLEDGEMENT}

We acknowledge all the USGS Breeding Bird Survey participants for their continuous effort. We are grateful to two anonymous reviewers for their constructive comments. This research as been funded by FONDECYT-FONDAP 1501-0001, Program 4, LincGlobal, ICM P05-002 \& Conicyt PFB-23.

\section{BIBLIOGRAPHY}

BONABEAU E, DAGORN L (1995) Possible universality in the size distribution of fish schools. Phys Rev E 51: R5220-R5223.

BONABEAU E, DAGORN L, FREÓN P (1999) Scaling in animal group-size distributions. Proc Natl Acad Sci USA 96: 4472-4477.
BROWN J, MARQUET P A, TAPER M (1993) Evolution of body size: consequences of an energetic definition of fitness. Am Nat 142: 573-584.

BROWN J (1995) Macroecology. Chicago: Chicago University Press.

CONT R, BOUCHARD J-P (2000) Herd behavior and aggregate fluctuations in financial markets. Macroecon Dyn 4: 170-196.

CHAVE J, LEVIN S (2003) Scale and scaling in ecological and economic systems. Env Res Econ 26: 527-557.

DOEBELI M, DIECKMANN U (2003) Speciation along environmental gradients. Nature 421: 259-264.

FISHER M, BARBER M (1972) Scaling theory for finite-size effects in the critical region. Phys Rev Let 28: 1516-1519.

FLIERL G, GRUNBAUM D, LEVIN S, OLSON D (1999) From individuals to aggregations: the interplay between behavior and physics. J Theo Biol 196: 397-454.

GASTON K, BLACKBURN T (2000) Pattern and Process in Macroecology. Oxford: Blackwell Science.

GISIGER T (2001) Scale invariance in biology: coincidence or footprint of a universal mechanism? Biol Rev 76: 161-209.

GOULD H, TOBOCHNIK J, WOLFGANG C (2006) An Introduction to Computer Simulation Methods: Applications to Physical Systems. Reading: Addison-Wesley.

GUERON S, LEVIN S (1995) The dynamics of group formation. Math Biosc 128: $243-264$.

HIGASHI M, YAMAMURA N (1993) What determines animal group size? Am Nat 142: 553-563.

HUBBELL SP (2001) The Unified Theory of Biodiversity and Biogeography. Princeton University Press.

IJIRI Y, SIMON HA (1975) Some distributions associated with Bose-Einstein statistics. Proc Natl Acad Sci USA 72: 1654-1657.

KEITT T, MARQUET P (1996) The introduced hawaiian avifauna reconsidered: evidence of self-organized criticality? J Theor Biol 182: 161-167.

KEITT T, STANLEY H (1998) Dynamics of north american breeding bird populations. Nature 393: 257-260.

KIRKPATRICK M, BARTON N (1997) Evolution of a species' range. Ecology 150: $1-23$.

MAJUMDAR S, SIRE C (1993) Exact dynamics of a class of aggregation models. Phys Rev Let 71: 3729-3732.

MANTEGNA RN, STANLEY HE (2000) Introduction to Econophysics: Correlations \& Complexity in Finance. Cambridge: Cambridge University Press.

MARQUET P A (2000) Invariants, scaling laws and ecological complexity. Science 289: 1487-1488.

MARQUET P A, QUIÑONES R, ABADES S, LABRA F, TOGNELLI M, ARIM M, RIVADENEIRA M

(2005) Scaling and power-laws in ecological systems. J Exp Biol 208: 17491769.

MARQUET PA (2002) The search for general principles in ecology. Nature 418:723.

MAURER B (1999) Untangling Ecological Complexity. Chicago: University of Chicago Press.

MAURER B (2005) Statistical mechanics of complex ecological aggregates. Ecol Complex 2: 71-85.

MCGILL BJ, ETIENNE RS, GRAY JS, ALONSO D, ANDERSON MJ, BENECHA HK, DORNELAS M, ENQUIST BJ, GREEN JL, HE F, HURLBERT AH, MAGURRAN AE, MARQUET PA, MAURER BA, OSTLING A, SOYKAN CU, UGLAND KI, WHITE EP (2007) Species abundance distributions: moving beyond single prediction theories to integration within an ecological framework. Ecology Letters 10: 9951015.

MILNE B, JOHNSON A, KEITT T, HATFIELD C, DAVID J, HRABER P (1996) Detection of critical densities associated with pinion-juniper woodland ecotones. Ecology 77: 805-821.

MOGILNER A, EDELSTEIN-KESHET L, BENT L, SPIROS A (2003) Mutual interactions, potentials, and individual distance in a social aggregation. J Math Biol 47: 353-389.

MORGAN M (1988) The effect of hunger, shoal size and the presence of a predator on shoal cohesiveness in bluntnose minnows, pimephales notatus rafinesque. J Fish Biol 32: 963-971.

NIWA H-S (1994) Self-organizing dynamic model of fish schooling. J Theor Biol 171: 123-136.

NIWA H-S (1996) Mathematical model for the size distribution of fish schools. Comp Math App 32: 79-88.

NIWA H-S (1998) School size statistics of fish. J Theor Biol 195: 351-361.

NIWA H-S (2003) Power-law versus exponential distributions of animal group sizes. J Theor Biol 224: 451-457. 
NIWA H-S (2004) Space-irrelevant scaling law for fish school sizes. J Theor Biol 228: 347-357.

NIWA H-S (2005) Power-law scaling in dimension-to-biomass relationship of fish schools. J Theor Biol 235: 419-430.

OKUBO A (1986) Dynamical aspects of animal grouping: swarms, schools, flocks, and herds. Adv Biophys 22: 1-94.

OKUBO A, LEVINS S (2001) Diffusion and the Ecological Problem: Modern Perspectives. New York: Springer-Verlag.

PASCUAL M, ROY M, GUICHARD F, FLIERL G (2002) Cluster size distribution: signatures of sef-organization in spatial ecologies. Phil Trans Roy Soc 357: 657-666.

PASCUAL M, GUICHARD F (2005) Criticality and disturbance in spatial ecological systems. Trend Ecol Evol 20: 88-95.

PETERJOHN B, SAUER J (1999) Population status of north american grassland birds from the north american breeding bird survey, 19661996. Stud Avian Biol 19: 27-44.

PUEYO S (2006) Diversity: between neutrality and structure. Oikos 112: 329 405.

RAJESH R, MAJUMDAR S (2001) Exact phase diagram of a model with aggregation and chipping. Phys Rev E 63: 036114.

RHODES B, JENSEN H, ANDERSON R (1997) On the critical behavior of simple epidemics. Proc Roy Soc Lond B 264: 1639-1646.

RINALDO A, MARITAN A, CAVENDER-BARES K, CHISHOLM S (2002) Cross-scale ecological dynamics and microbial size spectra in marine ecosystems. Proc Roy Soc Lond B 269: 2051-2059.

ROY M, PASCUAL M, FRANC A (2003) Broad scaling region in a spatial ecological system. Complexity 8: 19-27.

SORNETTE D (2000) Critical Phenomena in Natural Sciences. Heidelberg: Springer-Verlag.

STANLEY H (1987) Introduction to Phase Transitions and Critical Phenomena. New York: Oxford University Press.

STANLEY H (1995) Power laws and universality. Nature 378: 554

STANLEY H, AMARAL L, GOPIKRISHNAN P, IVANOV P, KEITT T, PLEROU V (2000) Scale invariance and universality: organizing priciples in complex systems. Physica A 281: 60-68.

STAUFFER D, AHARONY A (1992) Introduction to Percolation Theory. London: Taylor \& Francis.

STAUFFER D (2000) Grand unification of exotic statistical physics. Physica A 285: 121-126.

TAKAYASU H, NISHIKAWA I, TASAKI H (1988) Power-la mass distribution of aggregation systems with injection. Phys Rev A 37: 3110-3117.

TAKAYASU H (1989) Steady-state distribution of generalized aggregation systems with injection. Phys Rev Let 63: 2563-2565.

TAKAYASU M, TAKAYASU H (1989) Apparent independency of an aggregation system with injection. Phys Rev A 39: 4345-4347.

TAYLOR L, TAYLOR R (1977) Aggregation, migration and population dynamics. Nature 265: 415-421.

TURCOTTE DL (1999) Self-organized criticality. Rep Prog Phys 62: 13771429 .

VICSEK T, MEAKIN P, FAMILY F (1985) Scaling in steady-state clustercluster aggregation. Phys Rev A 32: 1122-1128.

VICSEK T (2001) Fluctuations and Scaling in Biology. Oxford: Oxford University Press.

WARBURTON K, LAZARUS J (1991) Tendency-distance models of social cohesion in animal groups. J Theor Biol 150: 473-488

YEOMANS J (1992) Statistical Mechanics of Phase Transitions. Oxford: Oxford University Press.

\section{ANNEX}

List of species analyzed:

American Coot (Fulica americana)

American Crow (Corvus brachyrhynchos)

American Goldfinch (Carduelis tristis)

American Kestrel (Falco sparverius)

American Robin (Turdus migratorius)

Baltimore Oriole (Icterus galbula)

Bank Swallow (Riparia riparia)

Blue-winged Teal (Anas discors)
Brewer's Blackbird (Euphagus cyanocephalus)

Canada Goose (Branta canadensis)

Chipping Sparrow (Spizell)

Common Grackle (Quiscalus quiscula)

Common Nighthawk (Chordeiles minor)

Common Raven (Corvus corax)

Common Snipe (Gallinago gallinago)

Common Yellowthroat (Geothlypis trichas)

Cliff Swallow (Petrochelidon pyrrhonota)

Double-crested Cormorant (Phalacrocorax auritus)

Downy Woodpecker (Picoides pubescens)

Eared Grebe (Podiceps nigricollis)

Eastern Bluebird (Sialia sialis)

Eastern Kingbird (Tyrannus tyrannus)

Eastern Phoebe (Sayornis phoebe)

Eastern Wood-Pewee (Contopus virens)

European Starling (Sturnus vulgaris)

Field Sparrow (Spizella pusilla)

Gadwall (Anas strepera)

Grasshopper Sparrow (Ammodramus savannarum)

Gray Catbird (Dumetella carolinensis)

Great Blue Heron (Ardea herodias)

House Finch (Carpodacus mexicanus)

House Sparrow (Passer domesticus)

House Wren (Troglodytes aedon)

Indigo Bunting (Passerina cyanea)

Killdeer (Charadrius vociferus)

Lark Bunting (Calamospiza melanocorys)

Lark Sparrow (Chondestes grammacus)

Loggerhead Shrike (Lanius ludovicianus)

Mallard (Anas platyrhynchos)

Mountain Bluebird (Sialia currucoides)

Mourning Dove (Zenaida macroura)

Northern Bobwhite (Colinus virginianus)

Northern Cardinal (Cardinalis cardinalis)

Northern Harrier (Circus cyaneus)

Northern Pintail (Anas acuta)

Pied-billed Grebe (Podilymbus podiceps)

Red-eyed Vireo (Vireo olivaceus)

Red-headed Woodpecker (Melanerpes erythrocephalus)

Red-tailed Hawk (Buteo jamaicensis)

Red-winged Blackbird (Agelaius phoeniceus)

Ring-billed Gull (Larus delawarensis)

Ring-necked Pheasant (Phasianus colchicus)

Rock Dove (Columba livia)

Rock Wren (Salpinctes obsoletus)

Song Sparrow (Melospiza melodia)

Swainson's Hawk (Buteo swainsoni)

Tufted Titmouse (Baeolophus bicolor)

Turkey Vulture (Cathartes aura)

Upland Sandpiper (Bartramia longicauda)

Vesper Sparrow (Pooecetes gramineus)

Warbling Vireo (Vireo gilvus)

Western Kingbird (Tyrannus verticalis)

Western Meadowlark (Sturnella neglecta)

Western Tanager (Piranga ludoviciana)

Western Wood-Pewee (Contopus sordidulus)

Yellow-billed Cuckoo (Coccyzus americanus)

Yellow-breasted Chat (Icteria virens)

a passerina) 